\title{
Характеристика микросфрер золы уноса для их использования в качестве сорбента
}

\author{
(С) 2019 Фоменко А.И. \\ Вологодский государственный университет, Вологда
}

Поступила в редакцию 3.06.2019 г.

DOI: $10.17308 /$ sorpchrom.2019.19/2231

Работа посвящена изучению физико-химических свойств микросфер золы уноса (зольных микросфер) тепловых электростанций с целью последующего их использования в качестве сорбента для очистки сточных вод от примесей различной природы. Определены химический и минералогический состав зольных микросфер. Выполнена оценка химической и механической стойкости, удельной поверхности, сорбционной способности материала. Анализ физических и химических свойств зольных микросфер показал, что исследованный материал соответствует требованиям ГОСТ Р 51641-2000 «Материалы фильтрующие зернистые. Общие технические условия» и является эффективным для использования, как в качестве самостоятельного сорбента, так и составляющей в системах водоочистки.

Ключевые слова: зола уноса, микросферы, сорбент, очистка воды.

\section{Characteristics of the microspheres of the ash dog for their use as a sorbent}

\author{
(C) 2019 Fomenko A.I. \\ Vologda State University, Vologda
}

\begin{abstract}
The physicochemical properties of aluminosilicate microspheres of fly ash (ash microspheres), isolated by filtering clarified water taken from a thermal power plant brightener pond, were studied in order to use them as a sorbent for purifying wastewater from various impurities.

To substantiate the possibility of using ash microspheres as a sorbent, their chemical and mineralogical composition, chemical and mechanical resistance, specific surface area, sorption capacity with respect to dyes congo red and methylene blue are determined. The mineralogical composition of the microspheres was obtained using X-ray phase analysis. Physical characteristics (equivalent grain diameter, heterogeneity coefficient), mechanical strength and chemical resistance indices of ash microspheres are determined according to GOST R 51641-2000 «Granular filter materials. General technical conditions». The specific surface area of microspheres is determined by methylene blue adsorption according to GOST 13144-79 (1999) «Graphite. Methods for determining the specific surface».

The studied material in terms of physical and chemical properties meets the requirements of GOST R 51641-2000 «Granular filtering materials. General technical conditions», is characterized by high chemical inertness and is effective for use, both as an independent sorbent and as a component in water treatment systems. The phase composition of the studied ash microspheres is represented mainly by the phase of mullite $\mathrm{Al}_{6} \mathrm{Si}_{2} \mathrm{O}_{13}$, a small content of the quartz phase $\mathrm{SiO}_{2}$ and X-ray amorphous glass phase. It is established that this material is an effective sorbent, both with respect to anionic and cationic dyes. The adsorption of congo red and methylene blue from a solution on the surface of the microspheres is satisfactorily described by the Langmuir model. The limiting sorption capacity of the studied samples of ash microspheres with respect to Congo red and methylene blue dyes is determined by similar values.
\end{abstract}

Keywords: fly ash, microspheres, sorbent, water purification. 


\section{Введение}

В настоящее время возрастает актуальность решения проблемы очистки сточных вод на основе разработки технологий, основанных на применении адсорбционных процессов с использованием в качестве сорбционной загрузки техногенных материалов. В настоящей работе в таком качестве исследованы микросферы золы уноса (зольные микросферы). Зольные микросферы, образующиеся при высокотемпературном сжигании каменных углей и считающиеся отходом тепловых электростанций, в действительности представляют собой перспективное сырье многоцелевого назначения. В процессе фракционирования зольных отходов выделяются магнитные микросферы, характеризующиеся высоким содержанием железа, и алюмосиликатные микросферы, обладающие ценными технологическими свойствами. Алюмосиликатные зольные микросферы представляют собой мелкодисперсный сыпучий порошок, состоящий из полых тонкостенных частиц сферической формы, наполненных газом. Значения насыпной плотности алюмосиликатных микросфер находятся в

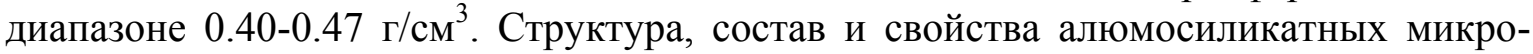
сфер изучались многими авторами [1-9]. Исследования [1] показали, что состав, структура и свойства алюмосиликатных микросфер определяются условиями сжигания и ассоциацией минералов в используемом топливе. Показано, что по фазовому составу алюмосиликатные микросферы золы уноса электростанций, работающих на кузнецком угле (Ново-Кемеровской ТЭЦ, Новосибирской ТЭЦ-5, Беловской и ТомьУсинской ГРЭС) [2-4], (Новочеркасской ГРЭС) [5] представляют смесь рентгеноаморфной стеклофазы и фазы кварца. Микросферы золы уноса Западно-Сибирской ТЭЦ, работающей на кузнецком угле, и Павлодарской ТЭЦ-2, работающей на экибастузском угле, характеризуются преимущественно фазой муллита с небольшим содержанием рентгеноаморфной стеклофазы [2]. Фазовый состав микросфер золы уноса Южно-Сахалинской ГРЭС представлен смесью фаз муллита, кварца и рентгеноаморфной стеклофазы, с преобладанием фазы муллита [6].

Особенности структуры, химического и минералогического состава алюмосиликатных микросфер, в сочетании с их уникальными технологическими свойствами, а также большими объемами образования и доступностью, определяют целесообразность их промышленного использования в качестве наполнителей композиционных материалов различного назначения: теплоизоляционных [10-12], полимеров $[4,13]$, цементов [14], силикатного кирпича [5] и др.

Перспективным направлением является использование зольных микросфер в качестве сорбентов для извлечения из сточных вод примесей различной химической природы: радиоактивных $[15,16]$, нефти и нефтепродуктов $[6,17]$.

Однако основные характеристики зольных микросфер, представленные в литературе, преимущественно описывают физико-механические и теплотехнические показатели (плотность, механическую прочность, размеры частиц, теплопроводность, температуру размягчения), что не достаточно при паспортизации для оценки возможности их использования в качестве сорбента.

Цель данного исследования - характеристика физических и физикохимических свойств зольных алюмосиликатных микросфер для их использования в качестве сорбента при очистке воды.

\section{Эксперимент}

В работе были использованы образцы алюмосиликатных микросфер золы уноса, выделенные фильтрованием осветлённой воды, отобранной из пруда- 
осветлителя Череповецкой ГРЭС. Ранее [18] данный материал был апробирован в лабораторных условиях в качестве сорбента ионов тяжелых металлов из водных растворов. Было установлено, что по размеру частиц зольные микросферы исследованных образцов представлены, в основном, смесью фракций класса крупности 0.630.16 мм (87.02 мас.\%), имеют среднюю плотность 0.452 г/см ${ }^{3}$, характеризуются химическим составом, мас.\%: $60.4 \mathrm{SiO}_{2} ; 26.1 \mathrm{Al}_{2} \mathrm{O}_{3} ; 4.7 \mathrm{Fe}_{2} \mathrm{O}_{3} ; 2.3 \mathrm{CaO} ; 1.2 \mathrm{TiO}_{2} ; 0.93$ $\left(\mathrm{Na}_{2} \mathrm{O}+\mathrm{K}_{2} \mathrm{O}\right) ; 0.69 \mathrm{MgO}$. Сорбционные свойства микросфер золы уноса были изучены по отношению к ионам железа. По результатам кинетических исследований было установлено, что продолжительность сорбции в течение 2 ч является достаточной для установления состояния равновесия, значения предельной сорбционной емкости по отношению к ионам железа, полученные в условиях эксперимента, составили $0.145 \mathrm{M} / \Gamma$.

При исследовании на данном этапе определены минералогический состав образцов зольных микросфер, их физические характеристики, показатели механической прочности и химической стойкости, площадь удельной поверхности. Для исследований образцы зольных микросфер высушивались при комнатной температуре $25^{\circ} \mathrm{C}$ до воздушно-сухого состояния, просеивались через набор сит с сетками по ГОСТ 6613 калибра от 2.5 до 0.16 мм.

Данные по минералогическому составу отобранных образцов зольных микросфер получены с использованием рентгенофазового анализа. Для рентгеноструктурных исследований готовились образцы зольных микросфер из ситового рассева фракции 0.315-0.16 мм, высушенные до воздушно-сухого состояния. Рентгеновское исследование проводилось по методу порошка в излучении $\mathrm{Cu}-\mathrm{K}_{\alpha}$ на компьютеризованном дифрактометре ДРОН-3М. Интервал съемки по углам отражения составлял 10-100 . Идентификация индивидуальных фаз и минералов на дифрактограммах образцов зольных микросфер проведена с использованием базы данных JCHDS (картотека PDF-2) и компьютерной системы поиска HASYS.

Физические характеристики (эквивалентный диаметр зерен $d_{3}$, коэффициент неоднородности $K_{H}$ ), показатели механической прочности и химической стойкости зольных микросфер определены по ГОСТ Р 51641-2000 «Материалы фильтрующие зернистые. Общие технические условия». Значения величины эквивалентного диаметра зерен $d_{\ni}$ и коэффициента неоднородности $K_{H}$ микросфер определены по данным ситового анализа материала. Механическая прочность материала определялась его измельчаемостью и истираемостью. Для определения химической стойкости материала проводили химический анализ кислотной, щелочной и нейтральной вытяжек после выдержки проб в статических условиях в течение одних суток. Площадь удельной поверхности зольных микросфер определена методом адсорбции метиленового голубого по ГОСТ 13144-79 (1999) «Графит. Методы определения удельной поверхности».

В экспериментах была выполнена оценка сорбционной способности образцов по отношению к красителям конго красному и метиленовому голубому, представляющих в водном растворе разнозаряженные формы. Сорбционные характеристики микросфер по отношению к красителям изучали в статическом режиме при температуре $25^{\circ} \mathrm{C}$ из водных растворов с концентрацией красителя от $0.5 \cdot 10^{-5}$ до $1 \cdot 10^{-4}$ моль/дм ${ }^{3}$ при соотношении твердой (Т) и жидкой (Ж) фаз 1:100. Растворы красителей в контакте с сорбентом выдерживали в течение 24 ч, 3 и 7 суток. По истечении заданного времени в растворе определяли остаточную (равновесную) концентрацию определяемых красителей. Определение исходной и остаточной концентрации определяемых красителей в растворе проводили фотометрическим методом на фотоколориметре КФК-2МП. Определение концентрации в растворе конго красного 
проводили при длине волны 540 нм, метиленового голубого при длине волны 670 нм с использованием кюветы с толщиной поглощающего свет слоя 50 мм на фоне холостой пробы. Эффективность сорбции оценивали путем сравнения значения исходной концентрации определяемых красителей в растворе с остаточной концентрацией после контакта раствора с сорбентом по результатам трех измерений. В процессе исследований $\mathrm{pH}$ раствора не корректировали. Измерения $\mathrm{pH}$ растворов проводили с использованием иономера И-130М.

\section{Обсуждение результатов}

Согласно данным рентгенофазового анализа исследованные зольные микросферы представлены смесью фаз муллита $\mathrm{Al}_{6} \mathrm{Si}_{2} \mathrm{O}_{13}$, кварца $\mathrm{SiO}_{2}$ и аморфной стеклофазы. В исследованных образцах основной фазой является муллит $(\mathrm{d}=0.540 ; 0.339$ нм). Дифрактограммы содержат меньшей интенсивности линии кварца $(\mathrm{d}=0.424$; $0.334 ; 0.245 ; 0.228 ; 0.181 ; 0.138$ нм). Данные рентгенофазового анализа хорошо коррелируют с макроэлементным составом микросфер. Значение величины показателя $\mathrm{Si} / \mathrm{Al}$ в исследованных образцах составляет 2.1 (для фазы муллита отношение $\mathrm{Si} / \mathrm{Al}$ равно 0.35).

Проведенные испытания на механическую прочность и химическую стойкость микросфер показали удовлетворительные результаты. Определено, что значение измельчаемости зольных микросфер находится в пределах $0.5 \%$, а истираемости - 0.1\%, прирост сухого остатка не превышает 4 мг/дм ${ }^{3}$. По ГОСТ Р 51641-2000 значение измельчаемости не должно превышать $4 \%$, истираемости - $0.5 \%$, прирост сухого остатка не более $20 \mathrm{мг} /$ дм $^{3}$. Значения величины эквивалентного диаметра зерен $d_{\ni}$ и коэффициента неоднородности $K_{H}$ равны 0.18 мм и 3.0 соответственно. Полученный результат определения $d_{3}$ близок к данным, приведенным в литературе. По данным $[2,4,6]$, размер частиц микросфер, полученных при сжигании угля разных электростанций, находится в диапазоне 60-550 мкм. Установленное относительно высокое значение коэффициента неоднородности согласуется с данными рентгенофазового анализа. Известно [2], что зольные микросферы, содержащие преимущественно фазу муллита, характеризуются рельефной и перфорированной морфологией оболочки.

Площадь удельной поверхности микросфер $S_{y d}$, м²/г, определена по формуле

$$
S_{y d}=\frac{V \cdot C \cdot N_{A} \cdot W_{o}}{m \cdot M},
$$

где $V$ - объем раствора красителя метиленового голубого, пошедший на титрование,

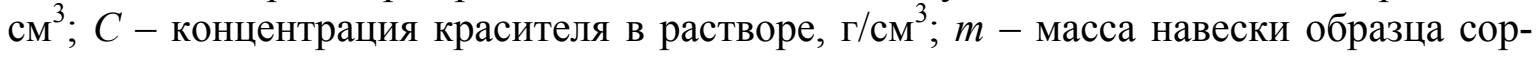
бента, г; $M$ - молярная масса метиленового голубого, равная 319.9 г/моль; $N_{A}-$ число Авогадро, равное $6.02 \cdot 10^{23} ; W_{o}$ - посадочная площадь молекулы метиленового голубого, равная 106 $10^{-20} \mathrm{M}^{2}$ (по ГОСТ 13144-79 (1999) «Графит. Методы определения удельной поверхности»).

Из полученных данных по величине объема раствора метиленового голубого, израсходованного на титрование суспензии зольных микросфер до появления окрашенного голубого ореола вокруг пятна капли суспензии на фильтре «синяя лента», была рассчитана площадь удельной поверхности материала, которая составила $1.8 \mathrm{~m}^{2} / \Gamma$. Сопоставление вычисленного значения площади удельной поверхности с результатами рентгенофазового анализа минерального состава показывает, что полученное значение соответствует приведенным в литературе данным для образцов зольных микросфер с перфорированной и рельефной поверхностью, содержащих преимущественно фазу муллита $[2,4]$. 
Из полученных экспериментальных данных адсорбционная емкость микросфер (образцов) определена по формуле

$$
\Gamma=\frac{\left(C_{0}-C_{\text {равн }}\right) \cdot V}{m},
$$

где $\Gamma$ - величина удельной адсорбции красителя при равновесии, моль/г; $C_{0}-$ концентрация красителя в исходном растворе, моль/дм ${ }^{3} ; C_{\text {равн }}-$ равновесная концентрация красителя в растворе, моль/дм ${ }^{3} ; V$ - объем раствора красителя, взятого для контактирования с образцом, дм³ $; m-$ масса навески образца, г.

Полученные результаты равновесных концентраций красителя в растворе для растворов с одинаковой исходной концентрацией при продолжительности сорбции 24 ч, 3 и 7 суток практически совпадают. Увеличение продолжительности сорбции до 3 и 7 суток не приводит к существенному изменению концентрации красителей в растворах. Особенно наглядно это проявляется для адсорбции конго красного. С учетом данных о продолжительности установления равновесия в изучаемых системах, параметры изотерм рассчитаны при продолжительности сорбции 24 ч.

Изотермы сорбции, построенные в координатах $\Gamma=f\left(C_{\text {равн }}\right)$ методом переменных концентраций определяемого красителя, представлены на рис. 1.

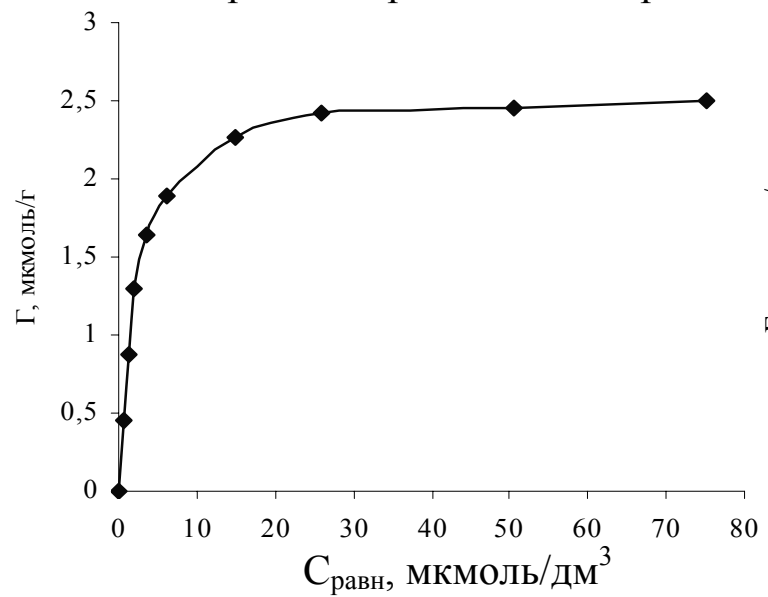

a

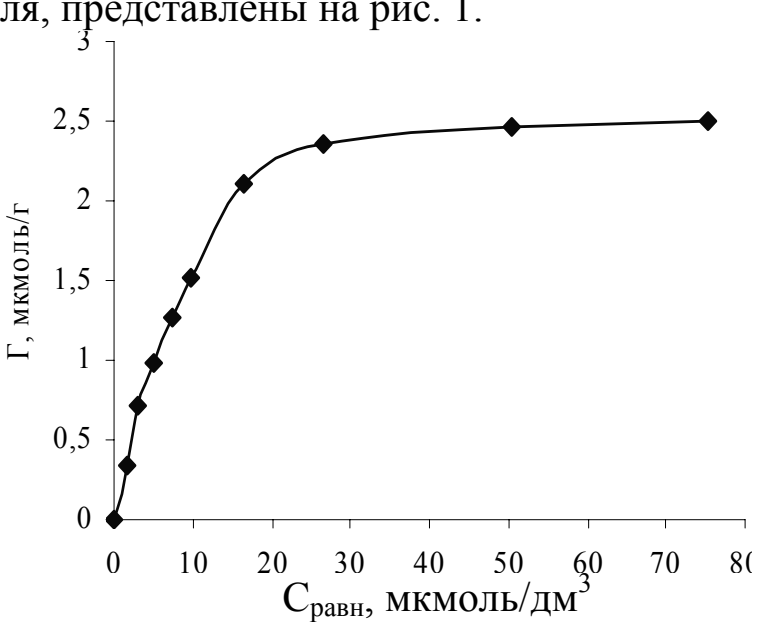

6

Рис. 1. Изотерма сорбции красителей конго красного (а) и метиленового голубого (б) из раствора зольными микросферами: - - экспериментальные данные, - - данные расчета по модели в программе MS Excell.

Полученные зависимости позволяют предположить, что извлечение красителей из раствора ограничивается мономолекулярной сорбцией на доступных для адсорбата центрах сорбции, расположенных в оболочке микросфер.

Значения величины предельной сорбционной емкости микросфер относительно анионов конго красного и катионов метиленового голубого рассчитаны по линейной форме уравнения изотермы Ленгмюра

$$
\frac{C_{\text {pass }}}{\Gamma}=\frac{1}{\Gamma_{\infty} k}+\frac{1}{\Gamma_{\infty}} C_{\text {past }}
$$

где $\Gamma_{\infty}-$ величина адсорбции при полном насыщении поверхности, моль/г, которая была определена по графику зависимости в координатах $\left(C_{\text {равн }} / \Gamma\right)=f\left(C_{\text {равн }}\right)($ рис.2); $k-$ константа сорбционного равновесия.

Рассчитанные значения предельной сорбции определяемых красителей из раствора зольными микросферами одного порядка. Предельная сорбционная емкость микросфер $\Gamma_{\infty}$ в условиях эксперимента при продолжительности сорбции 24 ч по отношению к анионам конго красного составила 2.557 мкмоль/г, катионам метиленового голубого 2.739 мкмоль/г. 


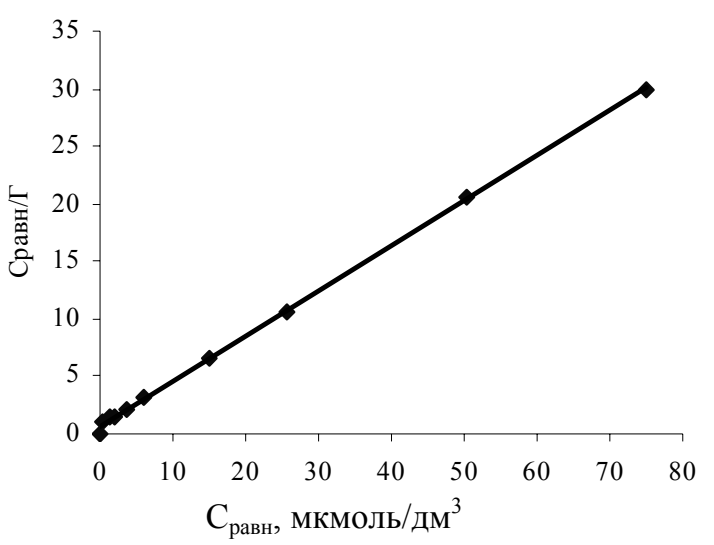

a

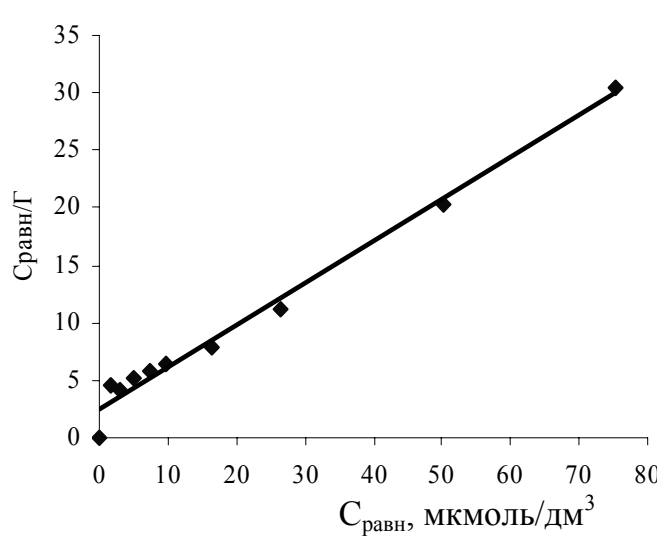

6

Рис. 2. Изотерма сорбции красителей конго красного (а) и метиленового голубого (б) из раствора зольными микросферами, линеаризованная в координатах уравнения Ленгмюра: - - экспериментальные данные, - - данные расчета по модели в программе MS Excell.

Изотермы сорбции красителей характеризуются высоким коэффициентом корреляции $\mathrm{R}^{2}$ : конго красного $\mathrm{R}^{2}=0.9993$, метиленового голубого $\mathrm{R}^{2}=0.9845$. Полученный результат показывает, что данный материал является эффективным сорбентом, как по отношению к анионным, так и катионным красителям.

\section{Заключение}

Выполненные исследования физических и физико-химических свойств зольных алюмосиликатных микросфер показали, что данный техногенный материал соответствует требованиям ГОСТ Р 51641-2000 «Материалы фильтрующие зернистые. Общие технические условия».

В результате исследований сорбционных свойств зольных микросфер, установлено, что адсорбция по отношению, как к анионным, так и катионным красителям, удовлетворительно описывается моделью Ленгмюра. Сорбционная емкость исследованных образцов зольных микросфер по отношению к красителям конго красный и метиленовый голубой определяется близкими значениями.

Таким образом, исследованный материал является эффективным для использования, как в качестве самостоятельного сорбента, так и составляющей в системах водоочистки.

Результаты исследования получены в рамках выполнения государственного задания Минобрнауки России (Задание № 11.9503.2017/8.9).

\section{Список литературы}

1. Данилин Л.Д. , Дрожжин В.С., Куваев М.Д., Пикулин И.В. и др. // Химия твердого топлива. 2008. № 2. С. 53-66.

2. Исмагилов 3.Р., Шикина Н.В., Журавлева Н.В., Потокина Р.Р. и др. // Химия твердого топлива. 2015. № 4. С. 49-57.

3. Верещагина Т.А., Аншиц Н.Н., Зыкова И.Д., Саланов А.Н. и др. // Химия в интере- сах устойчивого развития. 2001. Т. 9. С. 379391.

4. Теряева Т.Н., Костенко О.В., Исмагилов 3.Р., Шикина Н.В. и др. // Вестник КузГТУ. 2013. № 5. С. 86-90.

5. Котляр В.Д., Козлов А.В., Животков О.И., Козлов Г.А. // Строительные материальы. 2018. № 9. С. 17-21. 
6. Журавлева Н.В., Потокина Р.Р., Исмагилов 3.Р., Шикина Н.В. и др. // Химия в интересах устойчивого развития. 2014. Т. 22. С. 257-265.

7. Шаронова О.М., Аншиц А.Г., Соловьев Л.А., Саланов А.Н. // Химия в интересах устойчивого развития. 2010. Т. 18. С. 405-416.

8. Панкова М.В., Фоменко Е.В., Аншиц Н.Н., Верещагина Т.А.и др. // Химия в интеpесах устойчивого развития. 2010. Т. 18. С. 593-601.

9. Пименов В.Г., Никулин И.В., Дрожжин В.С., Сахаров А.М. // Химия твердого mоnлива. 2005. № 3. С. 83-92.

10. Адеева Л.Н., Борбат В.Ф. // Вестник Омского ун-та. 2009. № 2. С. 141-151.

11. Самороков В.Э. // Вестник ИрГТУ. 2012. T. 68. №9. C. 201-205.

12. Делицын Л.М., Рябов Ю.В., Власов А.С. // Энергосбережение. 2014.№ 2.С.59-66.

\section{References}

1. Danilin L.D. , Drozhzhin V.S., Kuvaev M.D., Pikulin I.V. et al., Khimiya tverdogo topliva, 2008, No 2, pp. 53-66.

2. Ismagilov Z.R., Shikina N.V., Zhuravleva N.V., Potokina R.R. et al., Khimiya tverdogo topliva, 2015, No 4, pp. 49-57.

3. Vereshchagina T.A., Anshic N.N., Zykova I.D., Salanov A.N. et al., Khimiya $v$ interesah ustojchivogo razvitiya, 2001, Vol. 9, pp. 379391.

4. Teryaeva T.N., Kostenko O.V., Ismagilov Z.R., Shikina N.V. et al., Vestnik KuzGTU. 2013, No 5, pp. 86-90.

5. Zhuravleva N.V., Potokina R.R., Ismagilov Z.R., Shikina N.V. et al., Khimiya $v$ interesah ustojchivogo razvitiya, 2014, Vol. 22, pp. 257265.

6. Kotlyar V.D., Kozlov A.V., Zhivotkov O.I., Kozlov G.A., Stroitel'nye materialy, 2018, No 9, pp. 17-21.

7. Sharonova O.M., Anshic A.G., Solov'ev L.A., Salanov A.N., Khimiya v interesah ustojchivogo razvitiya, 2010, Vol. 18, pp. 405- 416.

8. Pankova M.V., Fomenko E.V., Anshic N.N., Vereshchagina T.A. et al., Khimiya $v$ interesah ustojchivogo razvitiya, 2010, Vol. 18, pp. 593-601.

Фоменко Александра Ивановна - д.т.н., профессор, Вологодский государственный университет, Вологда
13. Варламова Л.П., Извозчикова В.А., Аверченко А.С., Семчиков Ю.Д. и др. // Журнал прикладной химии. 2008.Т. 81. №3. C. 502-504.

14. Данилин Л.Д., Дрожжин В.С., Куваем М.Д., Куликов С.А. и др. // Цемент и его применение. 2012. № 4. С. 100-105.

15. Данилин Л.Д., Дрожжин В.С. // Радиохимия. 2007. Т. 49. № 3. С. 283-286.

16. Васильева Н.Г., Верещагина Т.А., Аншиц Н.Н., Верещагин С.Н. и др. // Химия в интересах устойчивого развития. 2010. Т. 18. C. 231-237.

17. Новоселова Л.Ю., Погадаева Н.И. , Русских И.В., Сироткина Е.Е. // Химия твердого топлива. 2008. № 3. С. 63-69.

18. Фоменко А.И., Соколов Л.И. // Экология и промышленность России. 2019. Т. 23. № 1. C. 50-54.

9. Pimenov V.G., Nikulin I.V., Drozhzhin V.S., Saharov A.M., Khimiya tverdogo topliva, 2005, No 3, pp. 83-92.

10. Adeeva L.N., Borbat V.F., Vestnik Omskogo un-ta, 2009, No 2, pp. 141-151.

11. Samorokov V.E., Vestnik IrGTU, 2012, Vol. 68, No 9, pp. 201-205.

12. Delicyn L.M., Ryabov Yu.V., Vlasov A.S., Energosberezhenie, 2014, No 2, pp. 5966.

13. Varlamova L.P., Izvozchikova V.A., Averchenko A.S., Semchikov Yu.D. et al., Russian Journal of Applied Chemistry, 2008, Vol. 81, No 3, pp. 487-489.

14. Danilin L.D., Drozhzhin V.S., Kuvaem M.D., Kulikov S.A. et al., Cement i ego primenenie, 2012, No 4, pp. 100-105.

15. Danilin L.D., Drozhzhin V.S., Radiochemistry, 2007, Vol. 49, No 3, pp. 319-322.

16. Vasil'eva N.G., Vereshchagina T.A., Anshic N.N., Vereshchagin S.N. et al., Khimiya $v$ interesah ustojchivogo razvitiya, 2010, Vol. 18, pp. 231-237.

17. Novoselova L.Yu., Pogadaeva N.I. , Russkih I.V., Sirotkina E.E., Khimiya tverdogo topli$v a, 2008$, No 3, pp. 63-69.

18. Fomenko A.I., Sokolov L.I., Ekologiya $i$ promyshlennost' Rossii, 2019, Vol. 23, No 1, pp. 50-54.

Fomenko Aleksandra I. - Dr. Sci. (Tech), Professor, Vologda State University, Vologda, e-mail: fomenko1212@inbox.ru 